\title{
Infrequently Performed Studies in Nuclear Medicine: Part 1
}

\author{
Anita MacDonald and Steven Burrell \\ Department of Diagnostic Radiology, Queen Elizabeth II Health Sciences Centre and Dalhousie University, Halifax, \\ Nova Scotia, Canada
}

\begin{abstract}
Nuclear medicine is a diverse field with a large number of different studies spanning virtually all organ systems and medical specialties. Many nuclear medicine procedures are performed routinely; others may be performed only rarely, sometimes less than once per year. The infrequent nature of many studies makes it challenging to retain relevant knowledge and skills. This 2-part article provides a review of several infrequently performed studies. The topics discussed in Part 1 include dacroscintigraphy, LeVeen shunts, scintimammography, right-to-left shunts, leftto-right shunts, and heat-damaged red blood cells. After reading this article, the reader should be able to list and describe the indications for each study, list the doses and describe their proper method of administration, and describe problems that may arise during the imaging procedure and how they should be handled.

Key Words: infrequently performed studies; dacroscintigraphy; mammoscintigraphy; LeVeen shunt; right-to-left shunt; left-toright shunt; heat-damaged red blood cells
\end{abstract}

J Nucl Med Technol 2008; 36:132-143

DOI: $10.2967 /$ jnmt.108.051383

$\mathbf{T}$ he field of nuclear medicine is a broad one, with an extensive array of studies spanning virtually all aspects of medicine. Although some studies are routine, others are performed only rarely, sometimes less than once per year. Studies may be performed infrequently for a variety of reasons. For example, the condition they assess may be rare, imaging evaluation may not be routinely required for the given condition, there may be alternative imaging modalities, or there may be lack of awareness of the procedure on the part of ordering physicians. Although it is relatively easy to remain competent in studies performed on a daily basis, it can be difficult to retain knowledge of, and skills in, infrequently performed procedures. The purpose of this article is to provide a review of several such studies. The

\footnotetext{
Received Feb. 1, 2008; revision accepted May 7, 2008.

For correspondence or reprints contact: Anita MacDonald, Department of Diagnostic Imaging, Room 3016, 3 South Victoria, VG Site, Queen Elizabeth II Health Sciences Centre and Dalhousie University, 1278 Tower Rd., Halifax, Nova Scotia, Canada B3H 2 Y9.

E-mail: ajmacdon@dal.ca

*NOTE: FOR CE CREDIT, YOU CAN ACCESS THIS ACTIVITY THROUGH THE SNM WEB SITE (http://www.snm.org/ce_online) THROUGH SEPTEMBER 2010.

COPYRIGHT ( 2008 by the Society of Nuclear Medicine, Inc.
}

clinical and technical aspects of each study are discussed, along with a brief comparison of alternative assessment modalities. Included in Part 1 of this article are dacroscintigraphy, LeVeen shunts, scintimammography, right-to-left (R-L) shunts, left-to-right (L-R) shunts, and heat-damaged red blood cell (RBC) studies. Part 2 will cover cerebral spinal fluid shunt, brain death, testicular scan, quantitative lung perfusion scan, lymphoscintigraphy, and salivary gland scintigraphy studies.

\section{DACROSCINTIGRAPHY (LACRIMAL GLAND STUDY)}

The lacrimal glands are located in the lateral superior portion of each orbit. They are responsible for the production of tears that function to clean and lubricate the eyes. Tears are excreted from the lacrimal gland and transit across the surface of the eye to the nasolacrimal apparatus situated medial to the eye. The nasolacrimal apparatus, depicted in Figure 1, is responsible for draining the tears into the nasal cavity. It consists of 2 canaliculi, which receive the tears from the eye (superior and inferior portions) and converge to become the common canaliculus, which then empties into the nasolacrimal sac. Finally, fluid is drained from the nasolacrimal sac via the nasolacrimal duct into the nasal cavity. When this system is functioning normally, tear production and tear drainage are in balance.

Problems may arise when insufficient tear formation or an excess of tears occurs. Insufficient tear formation may be caused by a variety of medical problems including Sjögren's syndrome, inflammatory conditions, allergies, or radiation treatment, or the problem may be due to medications, age, or environmental conditions. Epiphora, or the overflow of tears, may be caused by an overproduction of tears, for example, because of irritation, allergies, emotions, or a variety of environmental factors. However, when patients present with epiphora, whether bilaterally or unilaterally, there may be a blockage of the nasolacrimal system that is prohibiting proper tear drainage. This obstruction may be functional or mechanical. A functional obstruction causing inefficient drainage may be due to medical issues such as facial palsy or exophthalmos. In these instances, the drainage system may be patent but is compromised by other conditions. In cases of mechanical obstruction, a portion of the nasolacrimal drainage system 


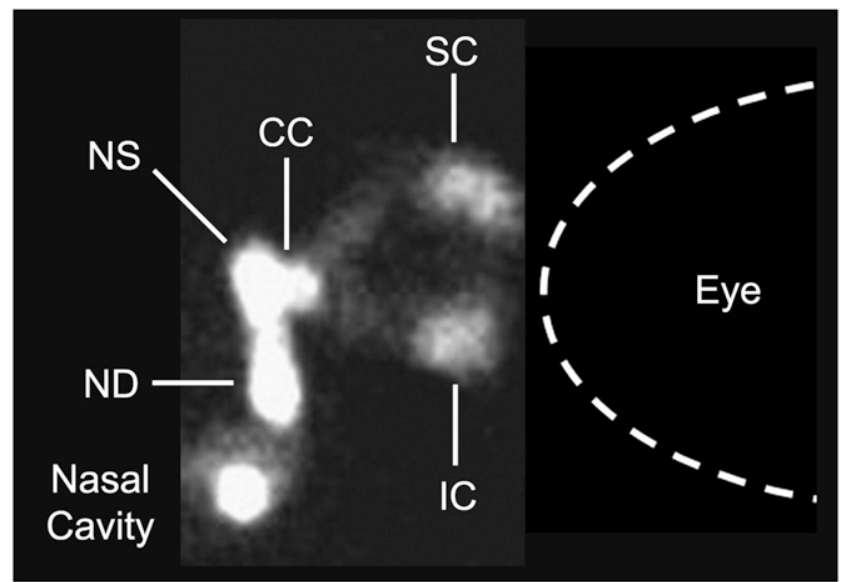

FIGURE 1. Nasolacrimal apparatus as seen on dacroscintigraphy. Nasolacrimal apparatus is situated medial to eye and consists of superior canaliculus (SC) and inferior canaliculus (IC), common canaliculus (CC), nasolacrimal sac (NS), and nasolacrimal duct (ND).

is obstructed. This may be due to inflammatory processes, a mucus plug, a dacrolith (stone), trauma, congenital abnormalities, or radiation therapy.

Dacroscintigraphy, the nuclear medicine lacrimal gland study, is a noninvasive, low-radiation-dose method of evaluating the nasolacrimal drainage system. It is used to demonstrate patency of the system and to localize the general area of obstruction, which can be important for presurgical planning. It also can be used postoperatively to evaluate whether the surgery was successful.

The patient must remove eyewear, including contact lenses, before starting the study. Approximately $3.7 \mathrm{MBq}$ $(0.1 \mathrm{mCi})$ of ${ }^{99 \mathrm{~m}} \mathrm{Tc}-$ pertechnetate in a saline solution is administered per eye (l) to the supine patient with an eyedropper or a needleless $1-\mathrm{mL}$ tuberculin syringe. It is critical to ensure that eyedrop administration is performed with care to prevent contamination of the patient's face with radioactive drops, which could interfere with interpretation of the study. If patients are teary, encourage them to blot, not smear, tears away with a tissue to limit potential of contamination. Encourage the patient to allow the tears to drain down the lateral aspect of the face; allowing the tears to fall this way is preferable to having them fall naturally anterior to the face, which may interfere with the imaging of the nasolacrimal duct and nasal cavity (Fig. 2). After the eyedrops are administered, the patient is placed in a sitting position for imaging. Immobilizing the patient's head may be necessary to obtain optimal imaging; this may include securing the patient's head to the camera face or using an immobilizing vacuum pillow to limit patient motion. A pinhole collimator (insert, 1-2 mm) or lowenergy all-purpose collimator with zoom may be used for acquisition. Dynamic or static imaging may be obtained. For dynamic imaging, use $10 \mathrm{~s} /$ frame for 1-2 min followed by $1 \mathrm{~min} /$ frame for $15-20 \mathrm{~min}$. Static imaging includes a 1-min image obtained immediately after the administration

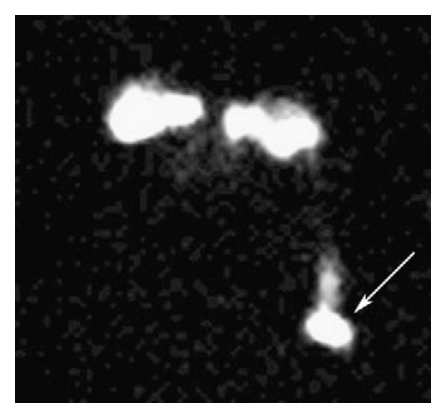

FIGURE 2. Tears usually deviate laterally, whereas true drainage pattern will reveal activity to deviate medially into nasal cavity. This case demonstrates patient with contamination from radioactive tears from left eye falling anteriorly down face (arrow).

of eyedrops, followed by 1-min static images obtained at 5 , 10,15 , and $20 \mathrm{~min}$. Visualization of the nasolacrimal sac within $1 \mathrm{~min}$ after eyedrop administration, with drainage of activity from the nasolacrimal duct into the nasal cavity within $5 \mathrm{~min}$, is considered a normal finding (2). Drainage through the nasolacrimal duct to the nasal cavity can be variable, however, and others consider visualization of the nasal cavity within 10-15 min a normal finding (3). Radioactivity not visualized after this time period may indicate a blockage. Given the possible interpatient variability, it is recommended that one side be compared with the other, rather than simply relying on quoted transit time values. Evaluating both eyes simultaneously will be better for recognizing subtle differences between the drainage of each eye. When comparing one eye with the other, one must assume that one eye is functioning normally and be aware that the bilateral obstruction of varying levels may exist. The radiation dose to the eye may be as low as 0.14 $\mathrm{mSv} /$ eye for an unobstructed eye and upward to $4 \mathrm{mSv}$ in the presence of an obstruction (4). Flushing both eyes with saline after the study is complete will help to clear remaining radioactivity (5).

Figure 3 shows a series of images taken from a normal dacroscintigraphy study, and Figure 4 shows an example of a patient with bilateral obstruction at the level of the nasolacrimal ducts. No drainage into the nasal cavity 30 min after eyedrop administration was demonstrated.

Ophthalmologists may choose to evaluate the nasolacrimal drainage system in the office with a dye or saccharin test. In these methods, a dye or saccharin solution is administered to the patient's eye; the patient verifies proper lacrimal drainage when the dye is presented in the mouth or the saccharin is tasted in the mouth. These methods can confirm patency of the drainage system, but they provide no information on location of an obstruction or the presence of partial obstructions. Further, false-positives can occur if patients are unable to taste the saccharin in their mouth or if the dye is present but simply not visualized.

Radiologic dacryocystography is an alternative imaging modality for assessing the nasolacrimal system. Although this modality may provide greater anatomic detail than its nuclear medicine counterpart, it is more invasive, delivers a higher radiation dose to the eye, and is not performed under physiologic conditions (the contrast is injected under pres- 
FIGURE 3. Normal lacrimal gland study at 3 time points demonstrating bilateral drainage from eyes into nasal cavity.

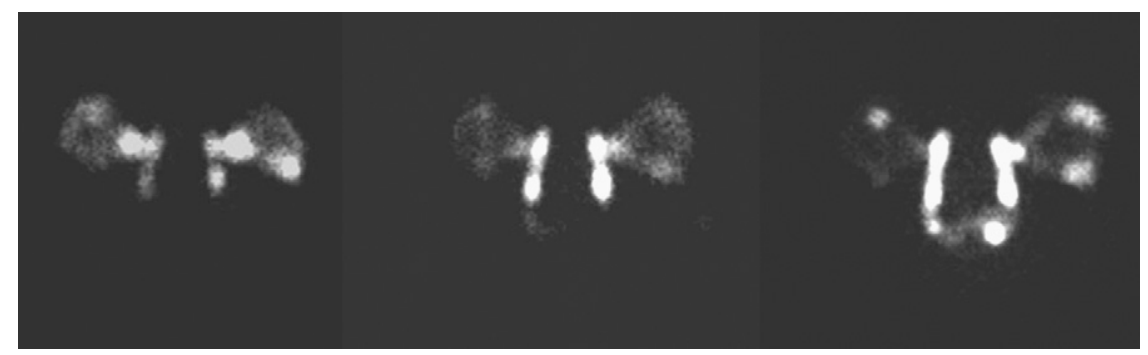

sure). It may also be more difficult to perform on postsurgical patients. For these reasons, it may be more beneficial to perform the nuclear study first and then only perform radiologic dacryocystography if necessary for diagnostic or therapeutic purposes.

\section{LEVEEN SHUNT STUDY}

The LeVeen shunt, introduced in the 1970s, was designed to help manage patients with chronic ascitis. Ascitis is a medical problem in which an excess of fluid accumulation in the peritoneal cavity occurs. This may be secondary to a variety of medical problems, including liver failure and kidney disease. The LeVeen shunt is a peritoneovenous shunt, intended to drain the ascites into the venous system. It is surgically placed in the peritoneal cavity and has a 1-way valve that connects into the patient's jugular vein, which then empties into the superior vena cava (SVC). The valve opens when the pressure in the abdomen exceeds the pressure in the SVC. Therefore, there should be an intermittent emptying of fluid from the peritoneal cavity into the venous system after proper LeVeen shunt placement. If the patient's ascitis is not alleviated after the shunt placement or if there is a subsequent recurrence of ascitis, several possibilities may be the cause, such as a worsening of the patient's condition, changes in the patient's diet, or changes in the patient's medical management. However, there may also be a mechanical obstruction in the tubing that is resulting in the ascitis accumulation. This may be caused by a valve malfunction or a thrombosis of the shunt tubing. A nuclear medicine LeVeen shunt study helps to identify whether the shunt is patent and rule out a mechanical obstruction. Studies have shown a sensitivity of $100 \%$ and a specificity of $92.2 \%$ for detecting shunt patency with this method (6).

No preparation is necessary for a LeVeen shunt study. The physician delivers an intraperitoneal injection of 185
$\mathrm{MBq}\left(5 \mathrm{mCi}\right.$ ) of ${ }^{99 \mathrm{~m}-\mathrm{Tc}-m a c r o a g g r e g a t e d ~ a l b u m i n ~(M A A) . ~}$ Local anesthetic may be administered before injection. After injection, the patient should be instructed to roll from one side to the other, which will facilitate mixing of the radioactive injection with the ascitic fluid. Widespread accumulation of the radioactivity should be visualized in the abdomen initially, confirming an appropriate injection. Static images of the abdomen and chest are obtained at 15 , 30,45 , and $60 \mathrm{~min}$ after injection. If required, images may be obtained up to $4 \mathrm{~h}$ after injection. Another study advocates performing breathing exercises during the study (7). These exercises are prescribed for maintenance purposes after placement of the peritoneovenous shunt and involve inhaling in resistance to $5 \mathrm{~cm}$ of water pressure. When the LeVeen shunt is functional, the injected ${ }^{99 \mathrm{~m}} \mathrm{Tc}-$ MAA travels to the lungs and lodges in the capillaries, as with a perfusion lung study. The lungs should become visualized within $1 \mathrm{~h}$ of imaging after the ${ }^{99 \mathrm{~m}} \mathrm{Tc}-\mathrm{MAA}$ intraperitoneal injection (Fig. 5). However, lung visualization may occur as early as $10 \mathrm{~min}(8)$.

${ }^{99 \mathrm{~m}} \mathrm{Tc}$-sulfur colloid has also been used as the radiopharmaceutical for a LeVeen shunt study. This method involves an intraperitoneal injection of $185 \mathrm{MBq}(5 \mathrm{mCi})$ of sulfur colloid with the liver as the target organ for confirmation of a functioning shunt. However, sulfur colloid is not the radiopharmaceutical preferred for this study because of the difficulty in discerning liver in the presence of radioactive ascitis in the abdominal images (9). In addition, the patient population being assessed may have diminished liver function and therefore the uptake of the sulfur colloid may not be preferential, regardless of the patency of the shunt.

Studies have shown that the shunt tubing itself may or may not be visualized and depends on the radiopharmaceutical used and the flow rate of the shunt. For example, the visualization of the tubing is greater with MAA than with sulfur colloid, and intermediate flow rates $(60 \mathrm{~mL} / \mathrm{h})$ tend to show the tubing better than do higher or slower flow

FIGURE 4. Dacroscintigraphy study demonstrating bilateral obstruction. Images at 3 time points reveal bilateral obstruction within nasolacrimal ducts (arrows).

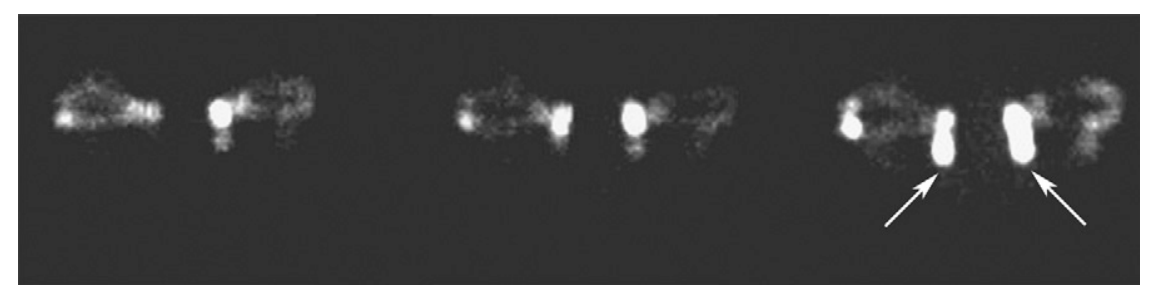




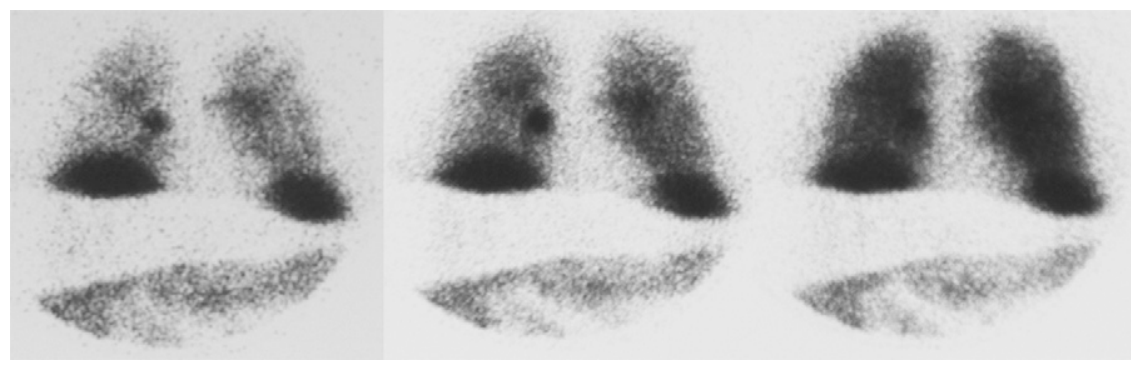

FIGURE 5. Normal LeVeen shunt study. Images at 10, 20, and 30 min demonstrate rapid arrival of $99 \mathrm{mTc}-\mathrm{MAA}$ in lungs with increasing activity over time, confirming patency of shunt. Activity inferior to lungs represents injected activity in peritoneal cavity.

rates (8). Because of the unreliable nature and variables involved in visualizing the shunt tubing, one should not use the parameter of tubing visualization to confirm shunt patency, and one should not expect to use this study to find the precise location of an obstruction.

The LeVeen shunt may also be evaluated by radiography using contrast. In this method, radiographic contrast is delivered directly into the shunt tubing. However, the pressure from contrast may release particles in the shunt into the circulation and has the potential to cause pulmonary emboli. The radiation exposure will also be higher using this method than it would with the nuclear medicine study. The value in the radiographic method lies in its ability to find the exact location of the obstruction, information that may not be found with the nuclear study. Ultrasound may also be used to assess shunt flow but requires patience and expertise. This may be especially difficult if the study is not performed frequently.

\section{SCINTIMAMMOGRAPHY}

Breast cancer is the most common malignancy of women in the Western world and, after lung cancer, is the second leading cause of cancer death in women. Early detection usually results in the most favorable outcome. The most advocated and noninvasive screening procedures include breast self-examination, physical examination by physician, and mammography. Although mammography is the most effective imaging modality for early detection of breast cancer, it may be difficult to differentiate benign from malignant lesions in certain patients, including those who have dense breast tissue or breast implants and those who have had previous breast surgery or radiation therapy. It is in these circumstances that further imaging evaluation may be required, and scintimammography has been shown to be an effective option. Studies have shown scintimammography to have an overall sensitivity of $83 \%$ and specificity of $93 \%$ in the noninvasive diagnosis of breast cancer in patients before biopsy, with a sensitivity of $94 \%$ in palpable abnormalities (10). Scintimammography may also help to identify axillary node involvement (11).

Scintimammography requires no specific patient preparation, but because of the private nature of the examination, professional conduct should be maintained throughout the study. For best results, the technologist should also ensure that the patient is aware of the steps of the procedure. After the patient's history is obtained and the study has been discussed, the patient is asked to remove all clothing and jewelry from the waist up. Hospital gowns should be supplied to the patient, with the first gown worn with the opening to the front and a second one used for privacy with the opening at the back until imaging begins. The patient is injected with $740-1,110 \mathrm{MBq}(20-30 \mathrm{mCi}){ }^{99 \mathrm{~m} T c-s e s t a m i b i}$ (12) in the arm contralateral to the breast with the suspected lesion. The injection should be administered through a 3-way stopcock mechanism or an intravenous catheter to ensure no dose infiltration. Infiltrated doses may cause lymph node uptake that could possibly be mistaken for a positive breast lesion or metastatic disease. If lesions are suspected in both breasts, or if the contralateral arm is not a viable option, a pedalis vein should be used as the route of administration.

Imaging may begin 5-10 min after injection. Reports have indicated no further detection of abnormalities from $10 \mathrm{~min}$ to $2 \mathrm{~h}$ after injection (13). For imaging purposes, the patient must remove one hospital gown to ensure proper positioning, which is crucial to obtain a high-quality study. The imaging routinely consists of 3 static acquisitions: left lateral breast, right lateral breast, and anterior chest (Fig. 6). Patients are positioned prone on the imaging table for the lateral views. An imaging table equipped with a mattress, preferably constructed with foam, with a cut-out for the breasts allows for better image quality and provides patient comfort. The prone position allows for the breasts to be maximally separated from the chest and abdominal wall. For example, positioning for the right lateral breast would involve the patient lying prone on the imaging table, as near the right edge of the bed as possible. The right breast would be positioned in a freely pendant position over the cut-out in the imaging mattress. Accidental compression of the breast against the table may cause false abnormalities (13); therefore, the breast must be hanging completely pendant. This position ensures that the left breast is lying flat against the imaging table and therefore no shine-through activity from the left breast will be visualized in the right lateral image. When imaging the lateral views, place the ipsilateral arm over the patient's head. The arm raised for each lateral view allows for visualization of the axilla. The imaging table may produce an artifact in the lateral statics. It appears as a line through the breast and may cause diffi- 
FIGURE 6. Anterior (A), left lateral (B), and right lateral (C) views of normal scintimammogram.

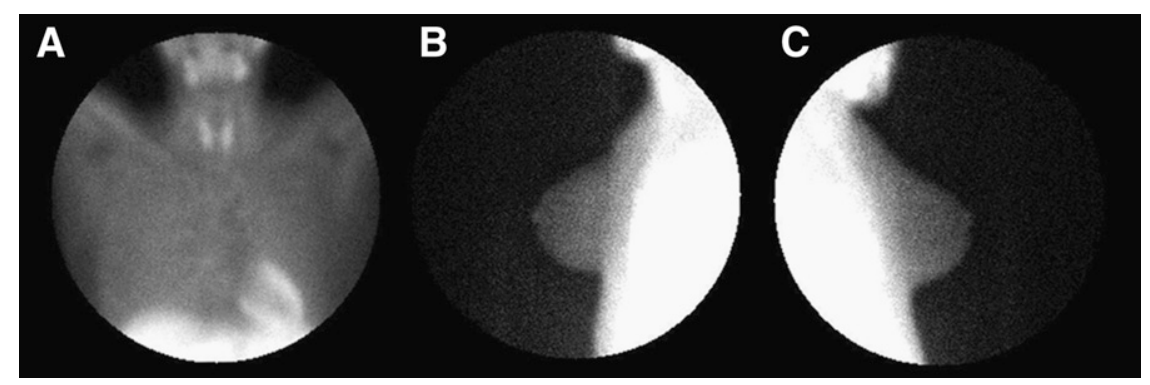

culty in evaluation of the image $(14,15)$. This may be minimized by placing the patient's shoulder and chest flat on the imaging table before imaging and also decreasing the photopeak window from the standard $20 \%$ to $10 \%$ $(14,15)$.

The anterior chest view is imaged with the patient in the supine position with the arms raised to include visualization of both axilla. Larger patients may require 2 statics in the anterior position to encompass each side of the chest. The camera is placed as near the patient as possible before imaging is started for all views. The patient's head may also be turned away from the collimator face, to mask the

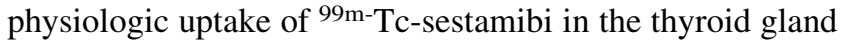
and salivary glands from the imaging views. Each static is taken for a total of 10 min with a 256 matrix with a parallelhole, high-resolution collimator. Zoom may be used to ensure abdominal organs and structures in the neck are excluded from the field of view.

${ }^{99 \mathrm{~m}} \mathrm{Tc}$-sestamibi is a lipophilic cation that accumulates in a variety of tumors through electrostatic association with mitochondria, which are often significantly increased in

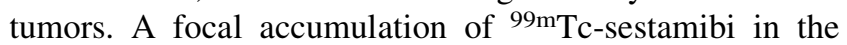
breast that is greater than the surrounding breast tissue is considered a positive finding (Fig. 7). Lesions less than 7-8 $\mathrm{mm}$ are less likely to be visualized with mammoscintigraphy because of the limited resolution of the $\gamma$-camera $(13,16)$. The location of the lesion in the breast may also inhibit visualization. For example, lesions close to the chest wall may be more difficult to identify than lesions that are farther away. A $30^{\circ}$ posterior oblique image is recommended if lesions are suspected close to the chest wall (14) to increase the sensitivity of finding the lesion (Fig. 8). False-positive findings may occur with benign hypercellu-

FIGURE 7. Abnormal accumulation of $99 \mathrm{mTc}$-sestamibi (arrow) in left breast consistent with malignancy. Biopsy confirmed infiltrating lobular carcinoma. lar lesions, inflammation, recent surgery, or biopsy. There have also been reports of ${ }^{99 \mathrm{~m}} \mathrm{Tc}$-sestamibi, or its breakdown byproducts, appearing in perspiration (16). Premenopausal patients may also show uptake in the breasts during the luteal phase of menses, so imaging within the first $10 \mathrm{~d}$ after menses would be optimal (16).

As noted earlier, standard mammography remains the most sensitive imaging modality for breast cancer. Ultrasound is frequently used in evaluation of breast abnormalities, primarily to determine whether a lesion is a cyst. When additional imaging is required for troubleshooting purposes, the main options are MRI and scintimammography. MRI has also been recently advocated as a screening tool in specific patient populations (17). PET using ${ }^{18} \mathrm{~F}-$ FDG has also been used as a means of assessing the breast in select patients with inconclusive mammograms. However, the true utility of PET in breast cancer is in assessing for metastatic disease by performing whole-body imaging, assessing response to therapy, and evaluating for tumor recurrence (18).

\section{R-L SHUNT STUDY}

The cardiovascular system may be divided into right and left systems. The right system consists of the venous system returning deoxygenated blood to the heart, the right side of the heart, and the pulmonary arteries delivering blood to the lungs for gas exchange. The left system consists of the pulmonary veins returning oxygenated blood to the heart, the left side of the heart, and the systemic arterial system delivering blood to the body. Normally no significant crossover between the systems occurs. However, a variety of

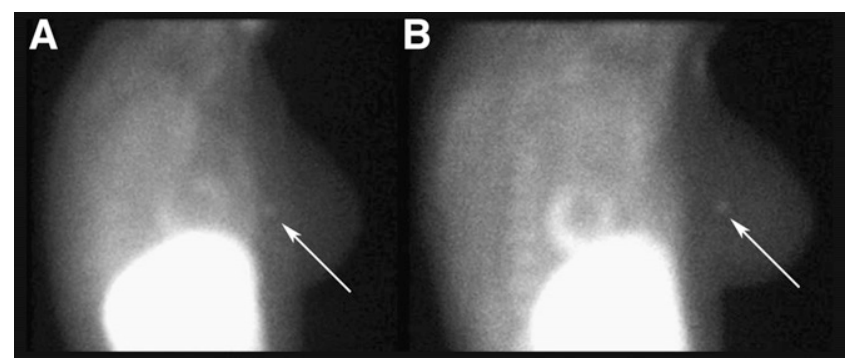

FIGURE 8. (A) Right lateral static view of scintimammogram. Small abnormal accumulation of activity is seen close to chest wall. (B) $30^{\circ}$ posterior oblique view significantly increases visualization of lesion. 
conditions can result in abnormal communication between the 2 systems, resulting in mixing of blood. These communications, known as shunts, may occur either within the heart or peripherally.

In R-L shunts, deoxygenated blood crosses into the left system, diluting the oxygenation being delivered to the systemic tissues and resulting in hypoxia. R-L shunts may arise from conditions within the lungs, such as pulmonary arterial-venous malformations, which may allow the incoming deoxygenated blood to bypass the capillary bed and pass into the left system without becoming oxygenated. Abnormal communications between the left and right sides of the heart, such as a ventricular septal defect (VSD), usually result in an L-R shunt, discussed in the next section, because of the higher left-sided pressures. However, under chronic conditions right-sided heart pressures often increase and may eventually even exceed left-sided pressures, causing a reversal of flow and an R-L shunt.

There are 2 nuclear medicine methods for detecting and quantifying R-L shunts. The first uses an intravenous injection of $99 \mathrm{~m}$ Tc-MAA. These particles are efficiently trapped by the pulmonary capillaries such that normally only about $3 \%$ of the activity is seen outside the lungs (19) (Fig. 9). The presence of an R-L shunt results in greater activity appearing within the systemic organs. Figure 10 is from an R-L shunt study in a 61-y-old male patient with cirrhosis of the liver resulting in hepatopulmonary syndrome. In this interesting syndrome, R-L shunts develop in the lungs secondary to the liver dysfunction. The shunts arise because of dilatation of precapillary vessels and direct arteriovenous communication. The etiology is not completely understood but is probably due to increased levels of circulating vasodilators, likely nitric oxide (20). The study demonstrates prominent increased uptake throughout various organs including brain, thyroid, spleen, kidneys, and bowel.

The percentage R-L shunt is expressed as the fraction of perfusion reaching the body outside the lungs to the total body perfusion including the lungs:

$$
\begin{aligned}
\% \mathrm{R}-\mathrm{L} \text { shunt }= & \text { systemic counts/whole-body counts } \times 100 \% \\
= & \text { whole-body counts }- \text { lung counts } / \text { whole- } \\
& \text { body counts } \times 100 \% .
\end{aligned}
$$

Variations of the analysis technique exist. For example, rather than drawing a region of interest (ROI) around the entire body to calculate the systemic perfusion, some have advocated using the activity in the brain and kidneys to estimate the total systemic perfusion. In this case, the activity in the brain and kidneys is scaled up to estimate the total systemic activity on the basis of the percentage of total perfusion going to these organs, which may be estimated using a second radiotracer or by assuming a standard relative perfusion to these organs of $45 \%$ of total cardiac output. As shown in Figure 10, we use a whole-body

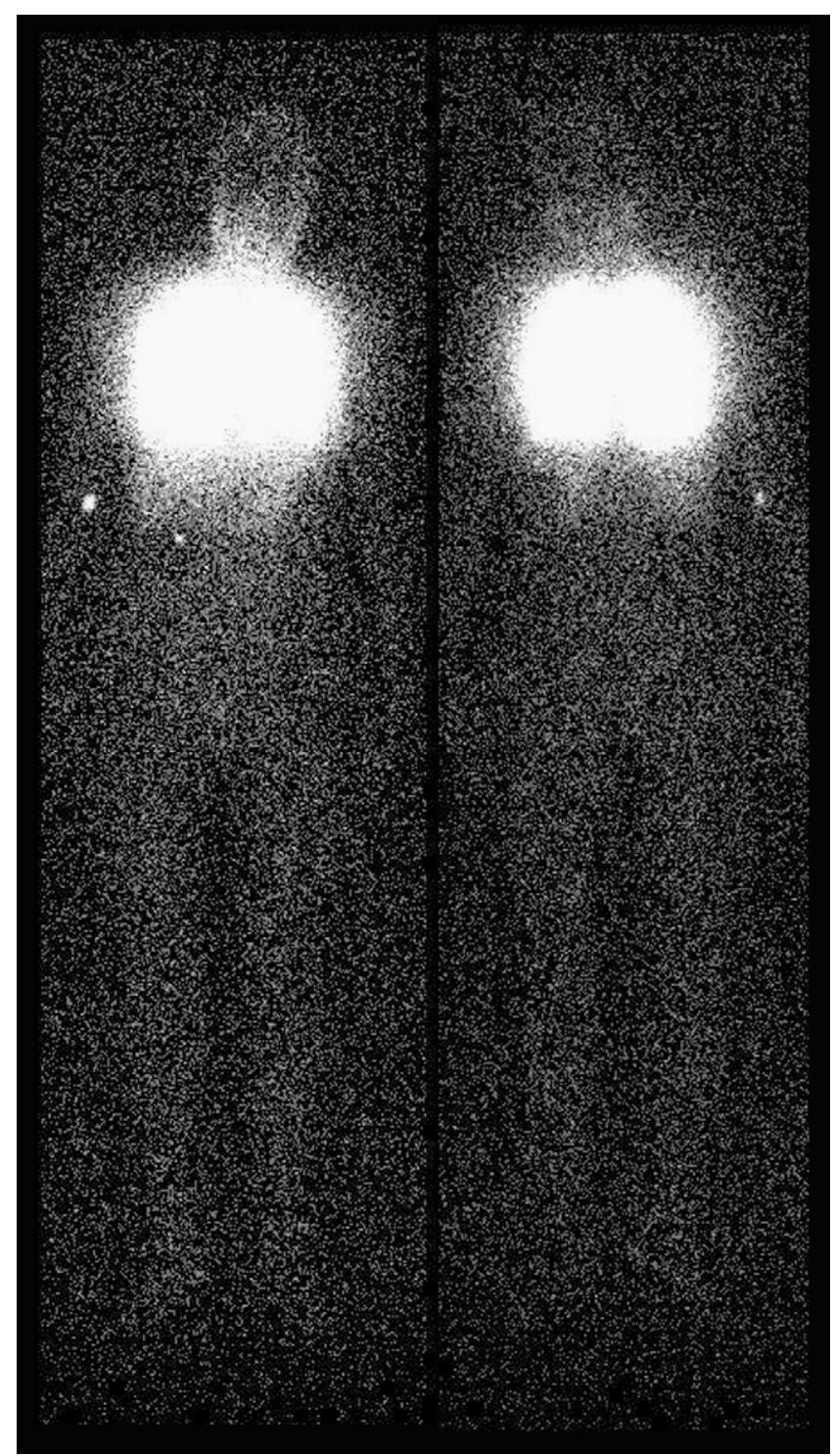

FIGURE 9. Relatively normal whole-body 99mTc-MAA study. Note little activity outside lungs.

acquisition with a dual-head camera. Activity in the lungs is assessed by placing ROIs around the lungs on both the anterior and posterior images and correcting for background activity in surrounding soft tissues with an ROI placed near the lungs. Activity in the whole body is assessed by placing ROIs around the entire body and correcting for background activity outside the patient. For both the lung activity and the whole-body activity, the geometric mean is used to estimate the true activity on the basis of measurements from the anterior and posterior images. The geometric mean, defined as the square root of the anterior counts multiplied by the posterior counts, is often used in nuclear medicine to estimate the true activity from anterior and posterior images and is more representative than the familiar arithmetic mean ([anterior counts + posterior counts]/2). In the patient in Figure 10, the R-L shunt was $41 \%$. 


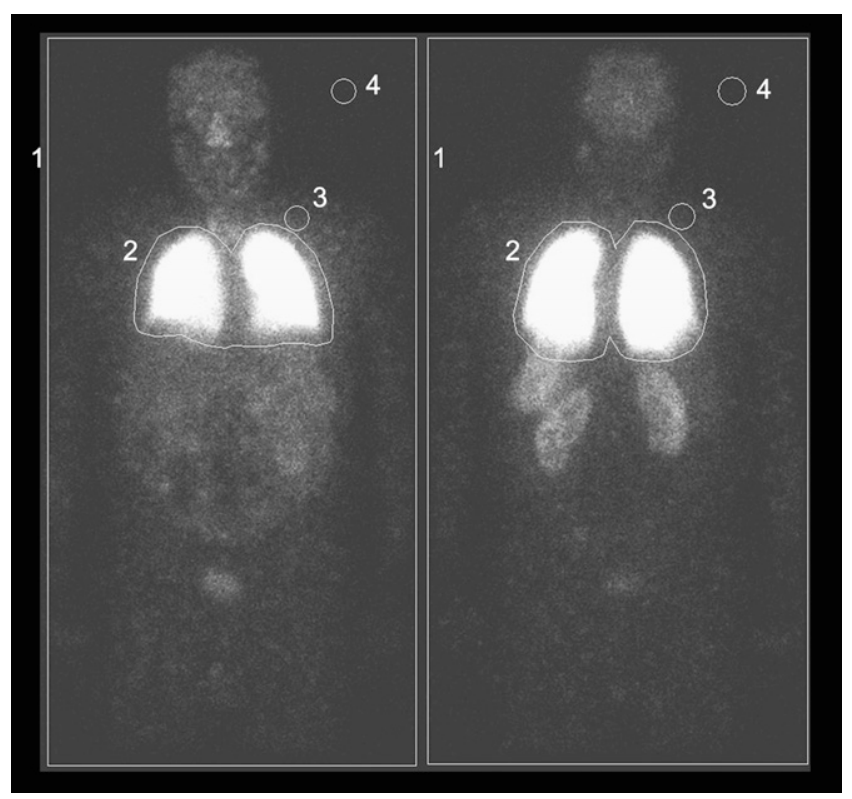

FIGURE 10. Whole-body ${ }^{99 m}$ Tc-MAA study in patient with $R-L$ shunting resulting from hepatopulmonary syndrome. Abnormal uptake, indicative of shunting, in several organs including brain, thyroid, spleen, kidneys, and bowel is shown. ROls around whole body (1), lungs (2), background soft tissue adjacent to lungs (3), and room background (4) are used in calculation of shunt (as discussed in text).

The injection of ${ }^{99 \mathrm{~m}} \mathrm{Tc}-\mathrm{MAA}$ particles in the setting of an R-L shunt carries the theoretic risk of causing microemboli in the brain and other critical organs. However, MAA studies in monkeys and subsequent histologic assessment have shown (21) that the possibility of inducing microembolic cerebral infarctions is remote. Scaling this monkey data to the clinical situation of performing an R-L shunt study in children, a 6,000:1 factor of safety has been estimated for the potential for inducing cerebral microemboli with a standard R-L shunt study (22). However, despite this reassuring information, it has been empirically recommended to reduce the number of particles injected to 10,000 (23). This can be done by injecting a fraction of a standard ${ }^{99 \mathrm{~m}}$ Tc-MAA kit, which will also result in a proportionally smaller radioactivity dose and noisier images. Alternatively, a kit of dilute MAA may be made up for R-L shunts, with a reduced number of particles relative to radioactivity. At our institution, we do this by first reconstituting a vial of MAA with $8 \mathrm{~mL}$ of saline (cold MAA). Cold MAA ( $1 \mathrm{~mL}$ ) is then withdrawn from the vial and dispensed into a sterile $10-\mathrm{mL}$ vial, along with $4.0 \mathrm{GBq}$ of ${ }^{99 \mathrm{~m}} \mathrm{Tc}$-pertechnetate. Routine quality control should then be performed. The radioactive vial of MAA is then diluted to a volume of $8 \mathrm{~mL}$ with saline. A patient dose of $74 \mathrm{MBq}$ $(2 \mathrm{mCi})$ in $0.15 \mathrm{~mL}$ of ${ }^{99 \mathrm{~m}} \mathrm{Tc}-\mathrm{MAA}$ is then immediately withdrawn and administered to the patient to ensure that the patient receives $10,000-20,000$ particles per $0.15-\mathrm{mL}$ dose.

The second nuclear medicine technique for evaluating $\mathrm{R}-\mathrm{L}$ shunts involves a first-pass approach. This technique is more commonly used in the evaluation of L-R shunts, as discussed in the next section; however, the first-pass approach for evaluating R-L shunts is slightly different. The primary ROI is the left ventricle rather than the lungs, as an R-L shunt will result in early appearance of activity within the left ventricle. R-L shunts may also be assessed during cardiac catheterization using the oxymetric method with blood sampling and oxygenation assessment within the different cardiac chambers and great vessels (24). However, this technique is more invasive than the nuclear medicine options.

\section{L-R SHUNT STUDY}

Shunts from the left system to the right system are frequently intracardiac, for example, when a defect in the septum allowing communication between the 2 sides of the heart exists. These may be between the 2 ventricles (ventricular septal defect), as shown in Figure 11, or between the 2 atria (atrial septal defect). Such abnormalities may initially be detected on routine stethoscope auscultation, as the turbulence associated with flow through the defect results in a heart murmur. The shunt results in already-oxygenated blood passing into the right heart and back to the lungs. To maintain an adequate amount of blood circulating throughout the body, cardiac output from the left side of the heart must increase to maintain normal forward flow through the aorta in the setting of abnormal flow being shunted to the right side of the heart. Output from the right side of the heart is also increased, as it must pump out both the normal
FIGURE 11. Two horizontal long-axis images from cardiac MRI in patient with VSD resulting in L-R shunt. Left image demonstrates defect (arrow) in IS. Right image is more inferior and demonstrates normal complete septum at this level. $\mathrm{RV}=$ right ventricle; IS = intraventricular septem; LV = left ventricle.
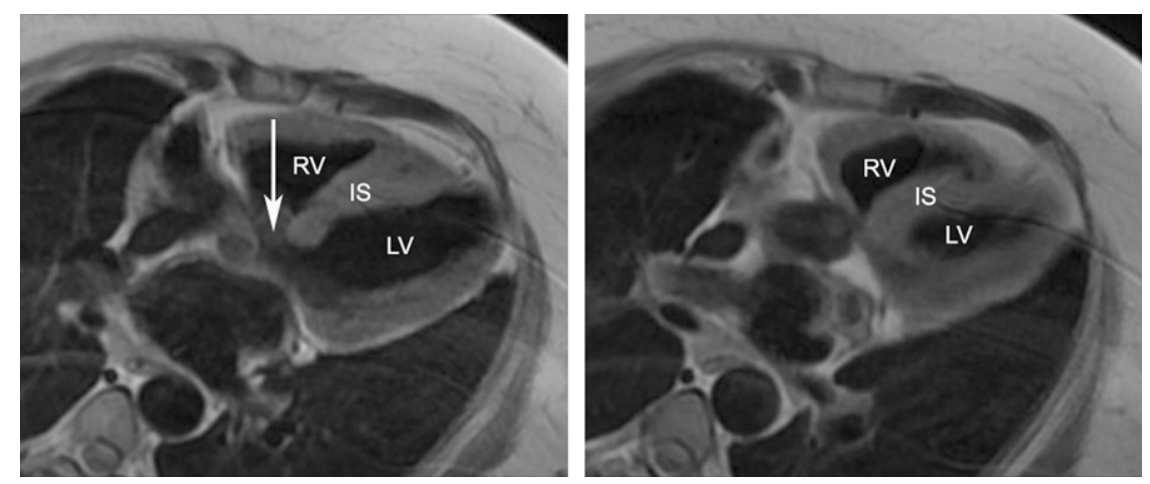


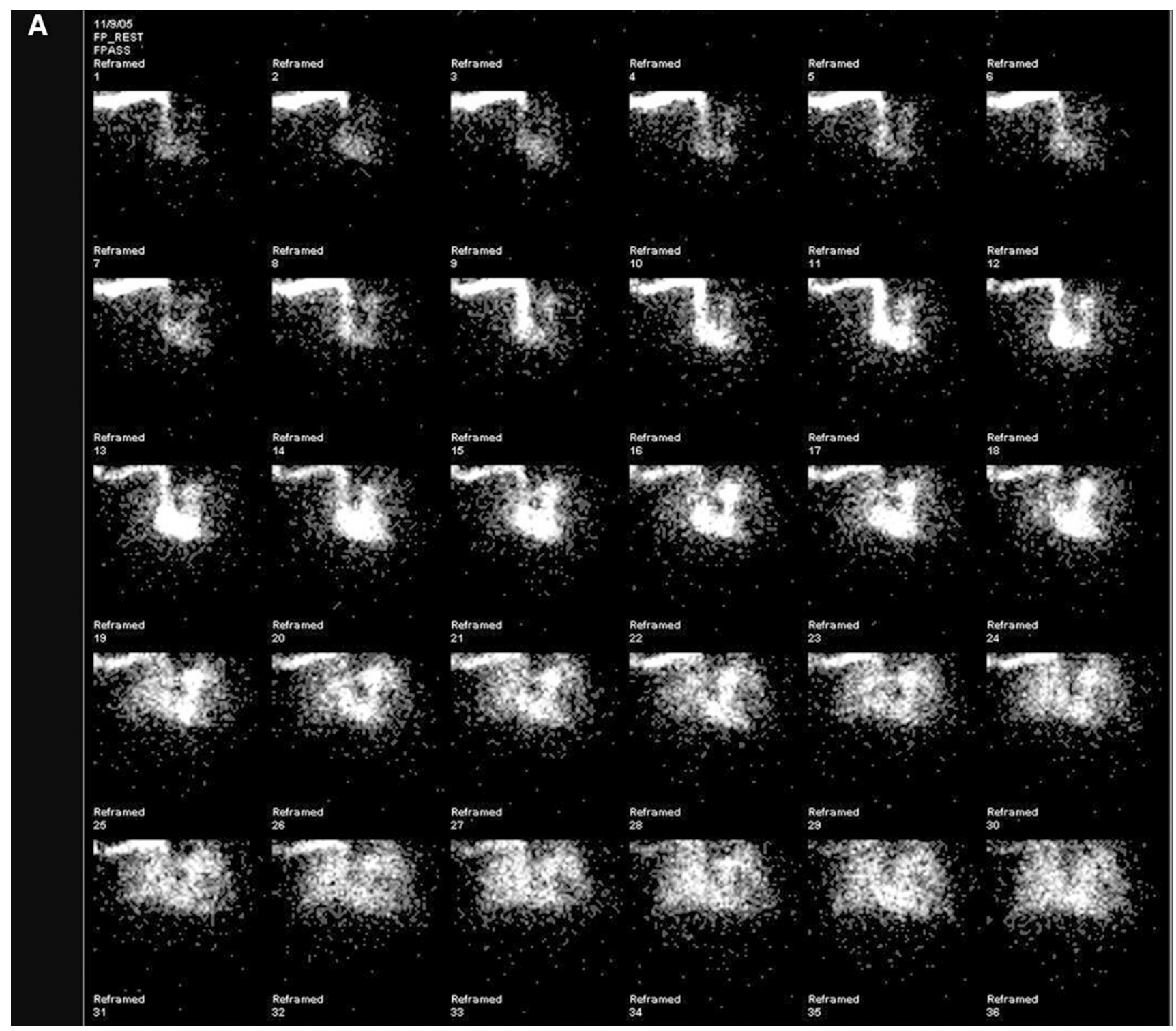

FIGURE 12. Normal first-pass L-R shunt study in same patient as in Figure 11. (A) Dynamic images demonstrate sequential arrival of activity in SVC, right side of heart, pulmonary arteries, lungs, pulmonary veins, and left side of heart. (B) Assessment of adequacy of bolus. ROI has been placed over SVC (square), allowing input activity to be plotted (C). FWHM is 1.18, indicating good tight bolus has been attained. (D) Time-activity curve over lungs. Total activity is demonstrated by solid line. $\gamma$-variate analysis has separated out lung curve (broken curve). Difference (curve) between total activity curve and lung curve is consistent with recirculation after first pass through body. There is no additional curve early after lung curve to suggest premature recirculation from $L-R$ shunt. This is reflected in analysis, which indicates normal $Q_{p} / Q_{s}$ of 1.00 . Consequently VSD is currently not physiologically significant.

volume of blood returning from the body plus the volume being shunted from the left heart. These effects can lead to elevated pulmonary pressures and heart failure.

Nuclear medicine assessment of an R-L shunt uses a firstpass analysis technique, in which a bolus of radiopharmaceutical is tracked using rapid dynamic imaging through the heart and lungs. The study is predicated on demonstrating early return of activity to the lungs after the initial flow there.

Careful attention to technique is important for the firstpass study (23). ${ }^{99 \mathrm{~m}} \mathrm{Tc}$-pertechnetate is most commonly used, although any ${ }^{99 \mathrm{~m}} \mathrm{Tc}-$ based radiopharmaceutical that remains within the circulatory system for the duration of the study can be used. The dose is $7.4 \mathrm{MBq} / \mathrm{kg}(0.2 \mathrm{mCi} /$ $\mathrm{kg}$ ) with a minima and maxima of $74 \mathrm{MBq}(2 \mathrm{mCi})$ and 740 MBq (20 mCi), respectively. A small volume such as 0.2 $\mathrm{mL}$ is necessary to help ensure a rapid, tight bolus injection, which is mandatory for this study. To help maintain the bolus, the injection should occur at a site with minimal distance to the right side of the heart. In theory, the right external jugular vein is best suited, but for practical purposes an antecubital vein is often substituted. An intravenous or butterfly catheter is used. A trial injection with 

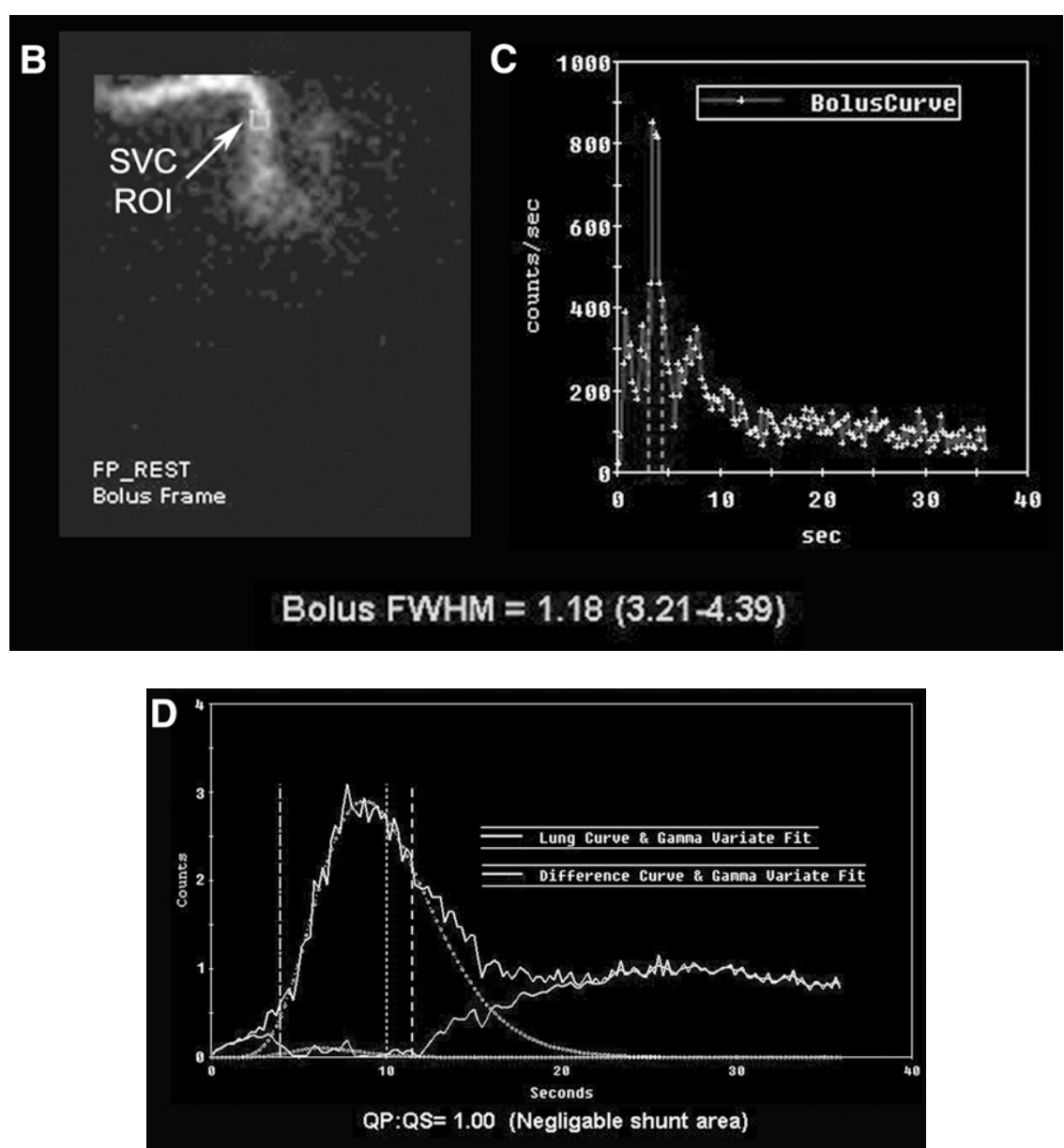

FIGURE 12. (Continued).

saline is performed to ensure proper flow. A rapid injection of the radiopharmaceutical is made with a bolus of saline administered directly after the radiopharmaceutical injection. The dynamic acquisition is begun coincident with, or even slightly before, the radiopharmaceutical injection. Dynamic imaging is obtained at 2-4 frames/s for $25 \mathrm{~s}$ on a $128 \times 128$ matrix. List mode may also be used. A parallelhole, high-efficiency collimator is used, with the camera centered over the thorax. The images may then be grouped and displayed for viewing purposes as shown in Figure 12A. The adequacy of the bolus is assessed by placing an ROI over the SVC and plotting the activity as a function of time as shown in Figures 12B and 12C. This should reveal a narrow bolus of activity with a full width at half maximum (FWHM) of less than $3 \mathrm{~s}$. If an inadequate bolus occurs, a second attempt can be made; some would advocate this be performed with a dose $50 \%$ greater than the original dose (19). If further attempts are required, these should be performed on another day. A valid study may still be obtained in the setting of a suboptimal bolus by applying deconvolution (25). This mathematical technique uses the input function, as measured over the SVC, to correct the data for the influence of the suboptimal bolus.
For the shunt analysis, an ROI is placed over each lung, being careful to avoid activity from the heart and great vessels. The lung activity is plotted as a function of time as shown in Figure 12D. Figure 13A is a schematic for a normal curve, reflecting normal flow through the lungs, consisting of an initial large peak with rapid upstroke representing the arrival of blood from the right ventricle and pulmonary arteries and subsequent downstroke reflecting the return via the pulmonary veins to the left atrium. Activity does not return completely to baseline. Several seconds later, there is a second peak of lower amplitude and less-steep ascent, representing recirculation as radiolabeled blood returns from the body and passes through the right side of the heart and onward to the lungs a second time. In the setting of an L-R shunt, there will be recirculation of radiolabeled blood through the right heart and onward to the lungs shortly after the initial bolus passes through the lungs, long before the return of blood from the body, as depicted in Figure 13B. This shunted activity begins to arrive during the downslope of the primary curve, resulting in a blunting of the rate of descent of the curve. As this curve represents the total activity in the lungs as a function of time, visually it may not be obvious how much is because of the primary 


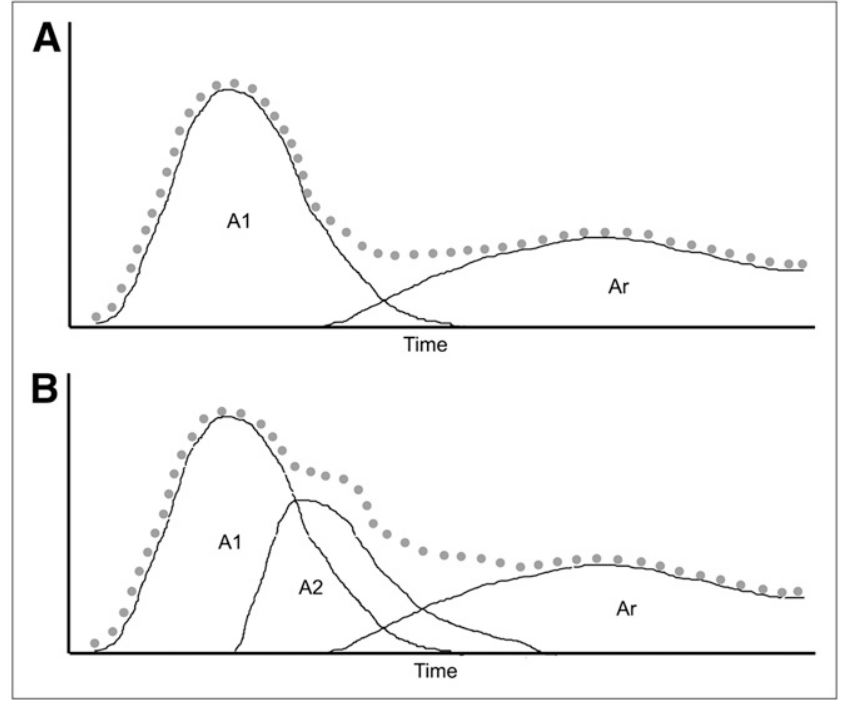

FIGURE 13. (A) Schematic of normal L-R shunt study. Dotted line reflects activity detected in lung ROI. $\gamma$-variate analysis deconstructs data into curves representing initial pass of activity through lungs, A1, and recirculated activity, Ar, after activity has circulated through body, back to heart, and onward through lungs again. (B) In setting of L-R shunt, there is reappearance of activity in lungs shortly after first pass, long before recirculation through body. This is detected as "bump" in downslope of time-activity curve. Magnitude of shunt is proportional to area under curve $A_{2}$.

flow versus the shunted flow. A mathematical technique known as $\gamma$-variate analysis is applied, which separates the total curve into 2 separate curves, one from the primary flow and a smaller, slightly later, curve from the shunted flow. The area under these curves $\left(A_{1}\right.$ and $A_{2}$, respectively) is proportional to the blood flow and is used to perform the shunt calculation. The magnitude of the shunt is expressed as the ratio of the pulmonary blood flow $\left(\mathrm{Q}_{\mathrm{p}}\right)$ to the systemic blood flow $\left(\mathrm{Q}_{\mathrm{s}}\right)$, where $\mathrm{Q}_{\mathrm{s}}$ equals the pulmonary blood flow less the shunt flow $\mathrm{Q}_{\text {shunt }}$ :

Shunt ratio $=\mathrm{Q}_{\mathrm{p}} / \mathrm{Q}_{\mathrm{s}}=\mathrm{Q}_{\mathrm{p}} /\left(\mathrm{Q}_{\mathrm{p}}-\mathrm{Q}_{\text {shunt }}\right)=\left(\mathrm{A}_{\mathrm{l}} /\left(\mathrm{A}_{1}-\mathrm{A}_{2}\right)\right)$.

Normally $\mathrm{Q}_{\mathrm{p}} / \mathrm{Q}_{\mathrm{s}}=1$, although values up to 1.2 may still be normal. The study is considered accurate in the $\mathrm{Q}_{\mathrm{p}} / \mathrm{Q}_{\mathrm{s}}$ range of 1.0-3.0, which is the most relevant range clinically.

Other uses of the first-pass technique include assessment of the ejection fraction from the right and left ventricles, although the latter is, of course, more commonly assessed using gated-wall motion studies, and assessment of R-L shunts, as noted in the preceding section. Note that when the first-pass technique is used to assess ejection fraction, a higher frame rate is necessary. Although echocardiography may be used in the assessment of L-R shunts in many situations, echocardiography can detect the presence of a shunt but cannot reliably quantify the shunt. The gold standard for shunt quantification is cardiac catheterization, which is invasive. Scintigraphy remains a minimally invasive means of quantifying L-R shunts.

\section{HEAT-DAMAGED RBC STUDY}

The heat-damaged, or heat-denatured, RBC study is used to assess for the presence and location of splenic tissue in a variety of clinical scenarios. One of the functions of the spleen is removal of damaged and obsolescent blood cells. Normal RBCs are deformable and pass readily through the spleen. However, through the process of heating, RBCs undergo fragmentation and spherocytosis, leading to increased stiffness and, consequently, entrapment by the spleen. This makes the heat-damaged RBC study a sensitive and specific method of identifying splenic tissue.

The main indications for this study are to identify accessory splenic tissue (also known as splenules or spleniculi) after surgical splenectomy for thrombocytopenia (low platelets), identify accessory splenic tissue after splenic trauma, assess whether a mass found on anatomic imaging, such as $\mathrm{CT}$, is a splenule, and assess congenital abnormalities of splenic number (asplenia or polysplenia) or splenic location (wandering spleen).

The study is performed by in vitro labeling of the patient's RBCs with $37-111 \mathrm{MBq}(1-3 \mathrm{mCi})$ of ${ }^{99 \mathrm{~m} T c}$ pertechnetate. The labeled RBCs are then heated in a water bath at $49.5^{\circ} \mathrm{C} \pm 0.5^{\circ} \mathrm{C}$ for $20 \min (26,27)$. Maintaining the specified temperature throughout the heating process is critical. Overheating will lead to excessive damage of the RBCs, resulting in increased uptake by the liver and decreased uptake by splenic tissue. Conversely, underheating will lead to insufficient damage of the RBCs. This too results in decreased splenic uptake, along with increased activity in the circulating blood pool. Other causes of excessive blood-pool activity include insufficient time between injection and imaging, poor splenic function, and absence of splenic tissue. As with all blood-labeling procedures, measures must be undertaken to ensure reinjection into the correct patient.

Because of the rapid splenic sequestration of the damaged RBCs, imaging can begin $30 \mathrm{~min}$ after injection. Planar and SPECT scans should be performed. When the study is a search for accessory splenic tissue, the entire abdomen must be imaged. The study may be done in the setting of prior trauma with splenic rupture to assess for implants of splenic tissue; if the diaphragm may have been violated during the trauma, then the thorax must be imaged as well to assess for implants there.

One of the most frequent indications for the study is to assess for the presence and location of splenic tissue in patients who have undergone surgical removal of the spleen in the setting of disorders such as idiopathic thrombocytopenic purpura (ITP), thrombotic thrombocytopenic purpura (TTP), and hereditary spherocytosis. These patients can develop dangerously low platelet levels as a result of excessive removal of platelets by the spleen. Thus, in severe 
cases the spleen is removed. However, small accessory spleens are common in the population, being present in one fifth to one third of postmortem studies. Consequently, patients may again develop low platelets even though their spleen has been removed. An option for therapy in this case is to locate and remove the accessory splenic tissue. The heat-damaged RBC study is the most effective method of identifying the splenic tissue. Figure 14 is such a study in a 56-y-old female patient whose platelet levels were falling significantly, despite previous splenectomy. A solitary intense focus of uptake is demonstrated in the splenic bed. Given its small size (the size is overestimated on these images because of limited resolution) it could not be identified on CT or MRI, even in retrospect. The patient went on to surgery, and a $\gamma$-probe was used intraoperatively to locate the splenule, which was then removed.

Figure 15 is from a 55-y-old female patient also undergoing evaluation for decreasing platelet counts in the setting of ITP. In this case, no accessory splenic tissue was identified. This case demonstrates that in the absence of significant functioning splenic tissue, the distribution of the damaged RBCs reflects the circulating blood pool.

Figure 16 demonstrates another indication for the heatdamaged RBC study. In this 65-y-old male patient, a CT scan performed for an unrelated reason identified a $3.1-\mathrm{cm}$ mass near the tail of the pancreas. The concern was that this could represent pancreatic cancer, although it was also near the splenic hilum and so it was suggested it may simply be a splenule. The nuclear medicine study clearly demonstrated that this was indeed a splenule, and no further workup was needed.

Accessory splenic tissue may also be identified on anatomic imaging such as ultrasound, CT, or MRI. However, as indicated by the above cases, these modalities are neither sensitive nor specific for splenic tissue. The heat-damaged RBC study is specific for splenic tissue and quite sensitive given the high contrast between splenules and surrounding tissues. A ${ }^{99 \mathrm{~m}} \mathrm{Tc}-$ sulfur colloid study is another nuclear medicine study that may be used to assess splenic tissue. However, the colloid is also taken up by the liver and bone marrow, and consequently this test is less sensitive and specific. The normal

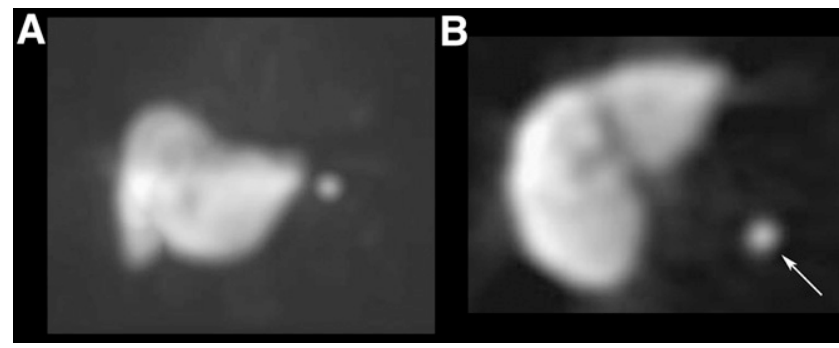

FIGURE 14. Heat-damaged RBC study assessing for presence of splenules in patient with ITP. Anterior MIP image $(A)$ and transaxial image (B) from SPECT acquisition demonstrate small but intense focus of uptake in splenic bed (arrow), consistent with splenule. MIP = maximum intensity projection.

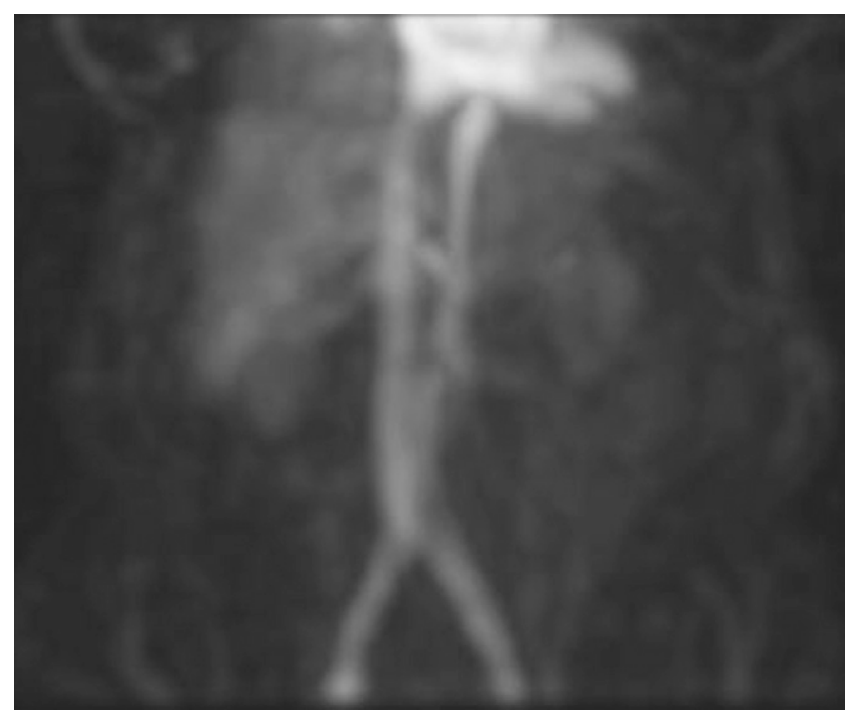

FIGURE 15. Anterior MIP image demonstrates no concentration of heat-damaged RBCs within accessory splenic tissue. This negative study depicts distribution of damaged RBCs throughout blood pool when there is no significant functioning splenic tissue to sequester them. MIP = maximum intensity projection.

spleen takes up only about $10 \%$ of injected ${ }^{99 m}$ Tc-sulfur colloid, versus $90 \%$ of heat damaged RBCs (28).

\section{CONCLUSION}

This review article has provided an overview of the clinical and technical aspects of 6 infrequently performed nuclear medicine procedures and may serve as a reference
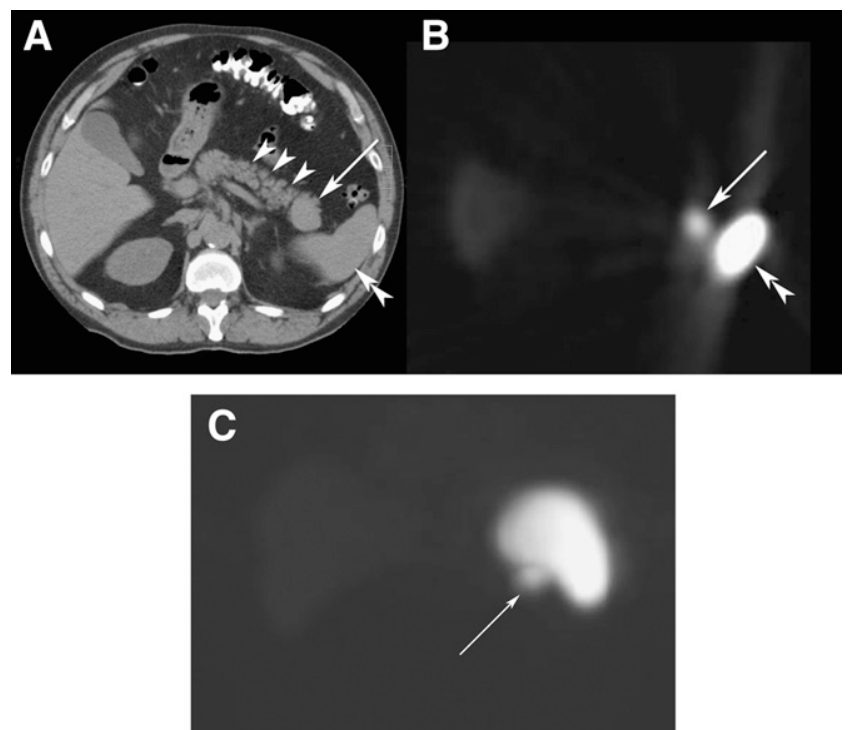

FIGURE 16. CT scan (A) revealed mass (arrow) near tail of pancreas (arrowheads) and spleen (double arrowhead). (B) Corresponding transaxial slice from heat-damaged RBC SPECT study demonstrates intense uptake in mass (arrow), confirming it is simply an accessory spleen. (C) Anterior MIP image further depicts uptake in mass (arrow) near splenic hilum. There is also intense normal uptake in spleen and faint uptake in liver. MIP = maximum intensity projection. 
for the technologist when confronted with one of these studies. Part 2 of this article will address 6 additional infrequent studies.

\section{REFERENCES}

1. Brown M, El Gammal TAM, Luxenburg MN, Eubig C. The value, limitations, and applications of nuclear dacryocystography. Semin Nucl Med. 1981;11:250-257.

2. Greyson ND. Lacrimal apparatus. In: Maisey MN, Britton KE, Collier BD, eds. Clinical Nuclear Medicine. 3rd ed. London, U.K.: Chapman \& Hall; 1998:567-572.

3. Sodee DB. Special imaging procedures. In: Early PJ, Sodee DB, eds. Principles and Practices of Nuclear Medicine. 2nd ed. St. Louis, MO: Mosby; 1995:802-818.

4. Packer S. The eye. In: Harbert J, ed. Textbook of Nuclear Medicine, Vol. II: Clinical Applications. Philadelphia, PA: Lea \& Febiger; 1984:144-154.

5. Von Denffer H, Dressler J, Pabst HW. Lacrimal dacryoscintigraphy. Semin Nucl Med. 1984;14:8-15.

6. Stewart CA, Sakimua IT, Applebaum DM, Siegel ME. Evaluation of peritoneovenous shunt patency by intraperitoneal Tc-99m macroaggregated albumin: clinical experience. AJR. 1986;147;177-180.

7. Gorten RJ. A test for evaluation of peritoneo-venous shunt function: concise communication. J Nucl Med. 1977;18:29-31.

8. Singh A, Grossman ZD, McAfee JG, Thomas FD. LeVeen shunt patency studies: clarification of scintigraphic findings. Clin Nucl Med. 1980;5:106-108.

9. Rosenthall L, Arzoumanian A, Hampson LG, Shennib H. Observations on the radionuclide assessment of peritoneovenous shunt patency. Clin Nucl Med. 1984;9:227-235

10. Villanueva-Meyer J, Leonard MH Jr, Briscoe E. Mammoscintigraphy with technetium-99m-sestamibi in suspected breast cancer. J Nucl Med. 1996;37: 926-930.

11. Taillefer R, Robidoux A, Lambert R, Turpin S, Laperriere J. Technetium-99msestamibi prone scintimammography to detect primary breast cancer and axillary lymph node involvement. J Nucl Med. 1995;36:1758-1765.

12. Miraluma ${ }^{\mathrm{TM}}$ kit for the preparation of technetium ${ }^{99 \mathrm{~m}} \mathrm{Tc}$ sestaMIBI for injection [package insert]. Wilmington, DE: Dupont Pharmaceuticals Company; 2000.
13. Peller PJ, Khedkar NY, Martinez CJ. Breast tumor scintigraphy. J Nucl Med Technol. 1996;24:198-203.

14. Diggles L, Mena I, Khalkhali I. Technical aspects of prone dependent-breast scintimammography. J Nucl Med Technol. 1994;22:165-170.

15. A guide to Miraluma ${ }^{\mathrm{TM}}$ breast imaging. Wilmington, DE: Dupont Pharmaceuticals Company; 1997.

16. Buscombe JR, Cwikla JB, Thakrar DS, Hilson AWJ. Scintigraphic imaging of the breast cancer: a review. Nucl Med Commun. 1997;18:698-709.

17. Saslow D, Boetes C, Burke W. American Cancer Society guidelines for breast screening with MRI as an adjunct to mammography. CA Cancer J Clin. 2007;57:75-89.

18. Moon DH, Maddahi J, Silverman DHS, Glaspy JA, Phelps ME, Hoh CK. Accuracy of whole-body fluorine-18-FDG PET for the detection of recurrent or metastatic breast carcinoma. J Nucl Med. 1998;39:431-435.

19. Treves S. Detection and quantitation of cardiovascular shunts with commonly available radiopharmaceuticals. Semin Nucl Med. 1980;10:16-26.

20. Leung AN. Case 63: hepatopulmonary syndrome. Radiology. 2003;229:64-67.

21. Kennady JC, Taplin GV. Safety of measuring regional cerebrocortical blood flow with radioalbumin macroaggregates [abstract]. J Nucl Med. 1966;7:345.

22. Gates GF, Orme HW, Dore EK. Measurement of cardiac shunting with technetium-labeled albumin aggregates. J Nucl Med. 1971;12:746-749.

23. Treves ST, Blume ED, Armsby L, Newburger JW, Kurac A. Cardiovascular system. In: Treves ST, ed. Pediatric Nuclear Medicine/PET. 3rd ed. New York, NY: Springer; 2007:128-161.

24. Davidson CJ, Bonow RO. Cardiac catheterization. In: Braunwald E, Zipes DP, Libby P, eds. Heart Disease: A Textbook of Cardiovascular Medicine. 6th ed. Philadelphia, PA: W.B. Saunders; 2001:359-386.

25. Ham HR, Dobbeleir A, Viart P, et al. Radionuclide quantitation of left-to-right cardiac shunts using deconvolution analysis: concise communication. $\mathrm{J} \mathrm{Nucl}$ Med. 1981;22:688-692.

26. Armas RR. Clinical studies with spleen-specific radiolabeled agents. Semin Nucl Med. 1985;15:260-275.

27. Royal HD, Brown ML, Drum DE, et al. Procedure Guideline for Hepatic and Splenic Imaging 3.0. Reston, VA: Society of Nuclear Medicine; 2003.

28. Atkins HL, Goldman AG, Fairchild RG, et al. Splenic sequestration of ${ }^{99 \mathrm{~m}} \mathrm{Tc}$ labeled heat treated red blood cells. Radiology. 1980;136:501-503. 